\title{
Resolution of peripheral artery catheter-induced ischemic injury in infants -Two case reports-
}

\author{
Sung Yong Park ${ }^{1}$, Dae Hee Kim ${ }^{1}$, Jin Soo Kim ${ }^{1}$, Kye Sook Kim ${ }^{1}$, You Sun Hong ${ }^{2}$, and Yong Woo Hong \\ Departments of ${ }^{1}$ Anesthesiology and Pain Medicine, ${ }^{2}$ Thoracic and Cardiovascular Surgery, Ajou University of College of Medicine, \\ Suwon, Korea
}

The occurrence of catheter-induced vasospasm of small caliber arteries is a well known complication of arterial catheterization in neonates. However, there is rare publication about these complications in infants. We report infants with peripheral ischemia caused by arterial catheterization of the femoral artery. (Korean J Anesthesiol 2010; 59: 127-129)

Key Words: Arteries, Cannulation, Complications, Infants.

One of the more serious complications of arterial catheterization is obstruction of the blood flow from the thrombi, emboli, and vasospasm, which leads to ischemia [1-4]. If end arteries are obstructed, the affected area becomes pale, cyanotic, cool, and motionless with an absent pulse. The standard intervention is to remove the catheter and then evaluate peripheral circulation for further treatment. Here, we describe two infants were provisionally diagnosed with catheter-induced vasospasm during arterial catheterization, and then treated successfully by intraarterial injection of lidocaine and papaverine.

\section{Case Reports}

\section{Case 1}

A 3-month-old girl weighting $6 \mathrm{~kg}$ was brought to the operating room for ventricular septal defect (VSD) repair without premedication. The baby was monitored with an electrocardiogram, automatic blood pressure cuff and pulse oximeters on toes of both feet. Anesthesia was induced with thiopental $25 \mathrm{mg}$ and vecuronium $1 \mathrm{mg}$ intravenous injection. The trachea was intubated with a tube with $4.0 \mathrm{~mm}$ in internal diameter without a cuff. Anesthesia was maintained with $4-6 \%$ of desflurane and $50 \%$ of oxygen and air. The baby was ventilated mechanically with $70 \mathrm{ml}$ tidal volume and 20 respiratory rate per minute.

After the tracheal intubation was performed, the right internal jugular vein and the left femoral vein were cannulated for the drug and fluid infusion and central venous pressure monitoring. The attempts were made to place a direct radial and femoral arterial line for arterial blood pressure monitoring several times without success. A surgical arteriotomy of left femoral artery

Received: August 27, 2009. Revised: 1st, September 22, 2009; 2nd, September 30, 2009. Accepted: November 11, 2009.

Corresponding author: Yong Woo Hong, M.D., Department of Anesthesiology and Pain Medicine, Ajou University of College of Medicine, San 5, Wonchoen-dong, Yeongtong-gu, Suwon 443-721, Korea. Tel: 82-31-219-5689, Fax: 82-31-219-5579, E-mail: ywhong7292@gmail.com (c) This is an open-access article distributed under the terms of the Creative Commons Attribution Non-Commercial License (http:// creativecommons.org/licenses/by-nc/3.0/), which permits unrestricted non-commercial use, distribution, and reproduction in any medium, provided the original work is properly cited. 
was performed and the artery was cannulated with a 22 gauge catheter for blood pressure monitoring. The arterial blood pressure was $98 / 42 \mathrm{mmHg}$, the heart rate was $154 / \mathrm{min}$, and the central venous pressure was $10 \mathrm{mmHg}$. The pulse oximeter showed $100 \%$ saturation and the skin temperature of both feet was $32.8^{\circ} \mathrm{C}$. The arterial blood pressure was maintained around $90 / 40 \mathrm{mmHg}$ under anesthesia. The skin temperature was $32.8^{\circ} \mathrm{C}$ on the right foot and was $32.2^{\circ} \mathrm{C}$ on the left at 5 minutes after the left femoral cannulation. At 10 minutes after left femoral cannulation, the temperature on the right foot was $33.4^{\circ} \mathrm{C}$ and $32.0^{\circ} \mathrm{C}$ on the left with a warm blanket covering the body. Although the oximeter on the right foot showed $100 \%$ saturation, the pulse oximeter on the left foot failed to show value after 5 minutes.

The catheter induced vasospasm in the left extremity was considered to occur. A warming device was applied to the left femoral area and $10 \mathrm{mg}$ of lidocaine was injected into the left femoral artery at 15 minutes after cannulation. The difference in the temperature of the right and the left foot began to decrease at 5 minutes after the treatment $\left(32.8^{\circ} \mathrm{C}\right.$ vs. $\left.32.0^{\circ} \mathrm{C}\right)$. The pulse oximeter of the left toe began to show $100 \%$ saturation at 15 minutes after treatment. The skin temperature of the right and left foot were $32.7^{\circ} \mathrm{C}$ and $32.2^{\circ} \mathrm{C}$ respectively at 20 minutes after treatment and were $32.9^{\circ} \mathrm{C}$ and $32.4^{\circ} \mathrm{C}$ respectively 25 minutes after treatment. The cardiopulmonary bypass was undergone at 55 minute after cannulation and was completed after VSD and patent ductus arteriosus repair. The skin temperatures of the right and the left foot were $31.5^{\circ} \mathrm{C}$ and $31.1^{\circ} \mathrm{C}$ respectively after completion of the cardiopulmonary bypass, the pulse oximeter continued to show $100 \%$ saturation. The baby was then discharged to intensive care unit (ICU) without any problem. The baby remained stable in the ICU and was discharged to the pediatric ward.

\section{Case 2}

A 6-month-old, $4.5 \mathrm{~kg}$ male infant was scheduled for surgical correction of VSD. After anesthesia was induced with $25 \mathrm{mg}$ of thiopental, endotracheal intubation was facilitated with $0.5 \mathrm{mg}$ of vecuronium. Anesthesia was maintained with desflurane and $50 \%$ of oxygen. Hemodynamic conditions after induction of anesthesia were stable. An arterial line via the right femoral artery was inserted with 22 gauge catheter. Arterial pressure curves obtained by the pressure line in the right femoral artery were without any technical problems.

The pulse oximeter on the right toe showed $100 \%$ saturation immediately after the placement of femoral arterial line, but failed to show any value at 5 minutes later, even though the oximeter on the left toe showed $100 \%$ saturation. The catheter induced vasospasm was suspected. A $3 \mathrm{mg}$ of papaverine was injected into the right femoral artery. Immediate after the papaverine injection, the pulse oximeter of the right toe began to show $100 \%$ and this technique had no effect on systemic arterial pressure for about 10 minutes. Surgery was performed without any problems and the postoperative course was uneventful.

\section{Discussion}

Tissue ischemia, resulting from embolization and/or vasospasm, is a known complication of arterial catheterization in neonate [1]. These complications do not seem to occur in infants frequently as much as in neonates. The insertion of arterial catheters or manipulation of arteries mechanically damages the vascular endothelium, exposing the subendothelial tissue and collagen to the circulating blood. Platelets then adhere and aggregate, releasing adenosine diphosphate and thromboxane $\mathrm{A} 2$ which is a platelet stimulator and a very potent vasoconstrictor. These events may lead to vasospasm around the catheter insertion site, complete occlusion, and tissue ischemia [5].

The diagnosis of acute ischemia in the neonatal population is usually based on clinical signs. Catheter induced vasospasm and tissue ischemia cause failure of showing any values of pulse oximeter on the same side of the extremity and a change in skin color and skin temperature. Although a Doppler signal may be audible in the distal extremity in many cases, the signal may be simply transferred and may not be an accurate reflection of the perfusion status of the limb [4]. Thus, for the early detection of the vasospasm, it is reasonable to monitor the temperatures or arterial saturations by pulse oximeter on both limbs. In our cases, the values on the pulse oximeter and the color and temperature of the skin in extremity were different from the other extremity. Therefore, a provisional diagnosis of catheter induced vasospasm was made and treated.

Age and weight have been considered risk factors for ischemic complications. With younger, lower-weight children more prone to complications. Catheter size in relation to the diameter of the vessel is also known to contribute to arterial spasm [6]. The incidence of these types of complications is not surprising because the vessels are generally very small and the infants who receive arterial lines are usually very ill with a decreased cardiac output and dehydration. Prolonged ischemia may produce cyanosis and discoloration of the skin and will lead to frank gangrene and irreversible tissue loss if not corrected [7]. However, arterial spasm typically resolves soon after injury, usually within 4 to 6 hours [8]. Most of the reports in the literature have shown that even though complications are rare, they can range from areas of skin necrosis and localized infections to ischemic necrosis of the finger tips or toes and gangrene. 
Historically, cases of acute limb ischemia in neonates have been treated conservatively, with occasional reports of complete recovery [4]. The usual treatment of ischemic injuries includes removal of the catheters, elevation of the affected limb, and warming of limb [5]. However, this method is not always successful, and tissue necrosis and loss may follow.

The pharmacologic treatment for catheter induced vasospasm includes nitroglycerin, papaverin, and lidocaine. The primary pharmacological effect of nitroglycerin is relaxation of the vascular smooth muscle, resulting in dilatation of the arterial and venous beds, counteracting the vasoconstriction from platelet aggregation. In smooth muscle cells, nitroglycerin is converted to nitrite ions and later to nitric oxide, activating guanylate cyclase and increasing the cells' cGMP. The elevated cGMP leads to dephosphorylation of the myosin light chain resulting in smooth muscle relaxation [9]. In addition to vasodilation, nitroglycerin can increase collateral circulation to areas of peripheral ischemia. Nitroprusside, primary mechanism of action is shared with nitroglycerin, may also play a role in treatment for vasospasm [10], because it relaxes arteriolar smooth muscle more specifically than nitroglycerine.

Papaverine, a commonly used spasmolytic, is an opium alkaloid that exerts a direct action an vascular smooth muscle, probably by an inhibition of oxidative phosphorylation and calcium flux during muscle contraction [11]. It has been demonstrated that systemic administration of papaverin reverses internal mammary artery vasospasm [12]. Seaber [13] demonstrated that drugs belonging to the papaverin group induced a rapid reversal of spasm, with a mean value from subjects showing $60 \%$ higher blood flow than that of control values in an experimental model. With papaverin, the spasm was not only reversed rapidly but also may have resulted in vasodilation.

Lidocaine did not significantly change blood flow. Several studies have demonstrated that the vasodilating effects of lidocaine are dose-dependent, with low doses producing vasoconstriction and high doses producing vasodilation [14]. In an experimental model, the author demonstrated that unlike papaverin, lidocaine was ineffective at reversing vasospasm, with flows approximately $50 \%$ to $60 \%$ of prespasm levels after a 30-minute period [13].

In the first case, the baby was treated with a warming device and a $10 \mathrm{mg}$ injection of intra-arterial lidocaine with a good result, even though lidocaine is known to have controversial antispasmolytic effect. Most studies with lidocaine as a spasmolytic in neonates were performed by topical application $[12,13]$. Reversal of catheter induced vasospasm in infant's lower limb may be attributed to conservative measures or spontaneous resolution.

Although there have been some reports that demonstrate the efficacy of the mentioned agents in vitro and in vivo [9-14], the selective intraarterial injection doses were not clarified, especially in infant. Thus, the babies were treated with a provisional dose of $10 \mathrm{mg}$ lidocaine and $3 \mathrm{mg}$ papaverine. The doses, especially lidocaine that demonstrated a biphasic response [14], should be clarified in further study.

In summary, we report two cases of tissue ischemia associated with femoral arterial line placement in an infant reversed by application of intra-arterial administration of $10 \mathrm{mg}$ lidocaine and $3 \mathrm{mg}$ papaverine. The controversial effect of lidocaine as a spasmolytic agent should be re-evaluated.

\section{References}

1. Braly BD. Neonatal arterial thrombosis and embolism. Surgery 1965; 58: 869-73.

2. Subhani M, Sridhar S, DeCristofaro JD. Phentolamine use in a neonate for the prevention of dermal necrosis caused by dopamine: a case report. J Perinatol 2001; 21: 324-6.

3. Wong AF, McCulloch LM, Sola A. Treatment of peripheral tissue ischemia with topical nitroglycerin ointment in neonates. J Pediatr 1992; 121: 980-3.

4. Friedman J, Fabre J, Netscher D, Jaksic T. Treatment of acute neonatal vascular injuries-the utility of multiple interventions. J Pediatr Surg 1999; 34: 940-5.

5. Baserga MC, Puri A, Sola A. The use of topical nitroglycerin ointment to treat peripheral tissue ischemia secondary to arterial line complications in neonates. J Perinatol 2002; 22: 416-9.

6. Mourot JM, Oliveira HM, Woodson LC, Herndon DN, Chung DH. Complications of femoral artery catheterization in pediatric burn patients. J Burn Care Res 2009; 30: 432-6.

7. White JJ, Talbert JL, Haller JA Jr. Peripheral arterial injuries in infants and children. Ann Surg 1968; 167: 757-66.

8. Flanigan DP, Keifer TJ, Schuler JJ, Ryan TJ, Castronuovo JJ. Experience with latrogenic pediatric vascular injuries. Incidence, etiology, management, and results. Ann Surg 1983; 198: 430-42.

9. Nicoara A, Abel M, Bronheim D, Thys D. Cardiovascular drugs. In: Anesthesiology. Edited by Longnecker DE, Brown DL, Newman MF, Zapol WM: Chicago, McGraw-Hill Company. 2008, pp 926-8.

10. Coppola J, Patel T, Kwan T, Sanghvi K, Srivastava S, Shah S, et al. Nitroglycerin, nitroprusside, or both, in preventing radial artery spasm during transradial artery catheterization. J Invasive Cardiol 2006; 18: 155-8.

11. Vardiman AB, Kopitnik TA, Purdy PD, Batjer HH, Samson DS. Treatment of traumatic arterial vasospasm with intraarterial papaverine infusion. AJNR Am J Neuroradiol 1995; 16: 319-21.

12. Hillier C, Watt PA, Spyt TJ, Thurston H. Contraction and relaxation of human internal mammary artery after intraluminal administration of papaverine. Ann Thorac Surg 1992; 53: 1033-7.

13. Seaber AV. Experimental vasospasm. Microsurgery 1987; 8: 234-41.

14. Evans GR, Gherardini G, Gürlek A, Langstein H, Joly GA, Cromeens $\mathrm{DM}$, et al. Drug-induced vasodilation in an in vitro and in vivo study: the effects of nicardipine, papaverine, and lidocaine on the rabbit carotid artery. Plast Reconstr Surg 1997; 100: 1475-81. 